\title{
Prevalence of malaria and typhoid fever and coinfection in all febrile patients attending at tertiary care hospital in Vadodara
}

\author{
Sangita Devubhai Vasava ${ }^{1 *}$, Sucheta Jitendra Lakhani ${ }^{1}$, Jitendra Devjibhai Lakhani ${ }^{2}$ \\ ${ }^{1}$ Department of Microbiology, SBKS MI RC, Vadodara, India. \\ ${ }^{2}$ Department of Medicine, SBKS MI RC, Vadodara, India.
}

\section{ARTICLE INFO \\ Article history: \\ Received on: March 27, 2021 \\ Accepted on: June 06, 2021 \\ Available online: September 01, 2021}

\section{Key words:}

Malaria, typhoid fever, coinfection, serological tests

\begin{abstract}
Malaria and typhoid fevers are common disorders of tropical countries, which can lead to substantial morbidity and mortality. It is an important cause of fever in India. The prevalence of malaria, typhoid, and their coinfection was studied at a tertiary care, rural-based teaching hospital. A total of 1,378 blood samples from febrile patients in whom initial diagnosis was of either malaria or typhoid fever were analyzed at the Department of Microbiology, SBKS Medical Institute and Research Centre, Pipalia, (District: Vadodara), India. The blood samples received from the outpatient department and also from the inpatient department of all age groups during January 2015-December 2019 were analyzed. The rapid diagnostic test and peripheral smear by Giemsa stain was carried out for diagnosis of malaria. Widal test was used for screening for typhoid which was further confirmed by blood culture and clinical diagnosis. Of the 1,378 febrile patients, 271 and 95 cases were diagnosed with typhoid fever and malaria, respectively. Coinfection was found in 18 (4.7\%) cases. Of the total 1,378 febrile patients initially screened for both these conditions, males and females were $50.7 \%$ and $49.3 \%$, respectively. Of the 95 patients of malaria, male preponderance was present ( $72.6 \%$ vs $27.4 \%)$, while typhoid had female dominance (male: $45.4 \%$; female: $54.6 \%$ ). The prevalence of malaria, typhoid, and coinfection was highest in the age group of 16-30 years, which was around $43 \%-45 \%$. The study revealed that the typhoid prevalence rate was higher than malaria in patients in whom initial diagnosis was made of either malaria or typhoid. Fever cases, in which either malaria or typhoid was suspected on basis of clinical symptoms $(27.86 \%$, 384 out of 1,378 samples), were having positive results of either malaria, typhoid, or both.
\end{abstract}

\section{INTRODUCTION}

Malaria and typhoid fevers have clinical symptoms, which are dominated by fever, and have two distinct pathogenic organisms with different modes of transmission [1]. Malaria is an acute febrile illness and is sometimes fatal. The five most important Plasmodium species are Plasmodium falciparum, Plasmodium vivax, Plasmodium malariae, Plasmodium ovale, and the new species Plasmodium knowlesi. The bites of female Anopheles mosquitoes transmit malaria. Transmission depends on the climatic environment that may affect the number and continued existence of mosquitoes, such as rainfall patterns, temperature, and humidity. In many places, transmission is seasonal and peaks

*Corresponding Author

Sangita Devubhai Vasava, Department of Microbiology, SBKS MI RC, Vadodara, India.E-mail: sangitavasava87@gmail.com during and just after the rainy season. Malaria epidemics can occur when the atmosphere and other conditions abruptly favor transmission in areas where people have minute or absence of immunity for malaria. People having low immunity move to areas with intense malaria transmission as refugees or migrant workers and develop severe diseases. According to the latest World Health Organization (WHO) malaria fact sheet, World Malaria Report, released on 30th November 2020, there were 229 million malaria cases and 409,000 malaria deaths in the world in 2019. The WHO region of Americas reported that the predominant parasite is $P$. vivax, representing $75 \%$ of malaria cases. The majority of malaria cases and deaths occur in subSaharan Africa. Half of the world's population was at risk of malaria in 2018. However, the WHO regions of southeast Asia, Eastern Mediterranean, Western Pacific, and the Americas are also at risk [2]. The diagnosis has to be accurate so that appropriate treatment for malaria which is a medical emergency 
can be instituted. Hence, specific investigation and accurate species identification is very important [3].

While typhoid fever causes systematic infection and is an important cause of fever and has global distribution [4]. The load of typhoid fever in low and middle-income countries is higher due to poor sanitation and unhygienic lifestyle [5]. Every year, the estimated cases of typhoid patients are 11-21 million, with around 128,000-161,000 deaths. Paratyphoid cases are estimated to be of 6 million per year with 54,000 deaths because of it. The majority of cases occur in south and southeast Asia and sub-Saharan Africa. The highest risk occurred in communities lacking access to proper sanitation, safe drinking water, and health education, the vulnerable group being children [6]. There are many Gram-negative enteric bacilli; however, Salmonella typhi, Salmonella paratyphi A, B, and $\mathrm{C}$ are more responsible for enteric fever. Transmission occurs through the fecal-oral route by contaminated hands as well as by contaminated food and water [7]. Typhoid patients can take few months to recover and may have socioeconomic significance [8]. Widal test is a useful diagnostic procedure for typhoid fever in developing countries like India, where in small hospitals and healthcare centers culture facility is not available [9].

A major public healthcare problem, malaria and typhoid fever are caused by organisms like protozoa and Gram-negative bacilli, correspondingly, in tropical and subtropical countries. They are transmitted by different mechanisms of actions [10]. There is a risk of contracting both infections simultaneously by people in endemic regions $[11,12]$. Here, both diseases have significantly overlapping clinical manifestations [13-16]. Therefore the resemblance of clinical symptoms may not lead to not proper diagnosis and there maybe exploitation of febrile patients $[14,17]$. Therefore, a reliable diagnostic method is important for treating such cases to reduce the use of incorrect medicines or disuse of drugs [14,16-18]. This study included both malaria and typhoid fever and coinfections incidence for all patients having fever.

\section{MATERIALS AND METHODS}

\subsection{Study Design and Study Site}

The present study is a prospective observational study carried out in the Microbiology Department at SBKS Medical Institute and Research Centre. Blood samples were 1,378 (January 2015December 2019) from patients of all age groups and were from both outpatient department and inpatient department collected from cases of all febrile patients in whom initial diagnosis of either malaria or typhoid fever was made. It was carried out at a tertiary care hospital attached to the medical college situated at Piparia, Vadodara district.

\subsection{Samples}

The present study included 1,378 samples of febrile patients at a tertiary care hospital. The patients presented clinically with fever and other indicative symptoms of malaria and typhoid fever. $5 \mathrm{ml}$ of whole blood sample was collected into the ethylenediaminetetraacetic acid bulb by venipuncture [19]. The diagnosis of malaria was carried out by using the following techniques.

\subsubsection{Thick and thin blood smears}

For blood smears, clean $26 \mathrm{~mm} \times 76 \mathrm{~mm}$ glass slides were used for thick and thin smears, prepared according to the standard method on it and the smears were stained with Giemsa stain. Thick and thin smears were determined according to the standard book [20].

\subsubsection{Detection of antigen}

A total of 1,378 samples were tested by rapid diagnostic test with the Malascan Pan/Pf kit for the detection of malaria. In the malaria kit, a membrane strip contained parasite lactate dehydrogenase $(\mathrm{pLDH}) /$ histidine-rich protein 2 (HRP2) in which $\mathrm{pLDH}$ was responsible for $P$. vivax and HRP2 for $P$. falciparum species. In the whole blood sample $5 \mu \mathrm{l}$ was added. Afterward, two drops of the assay buffer was added into the buffer well. Then, after 20 minutes the results were obtained.

\subsection{Typhoid Fever Detection}

Widal slide test (Beacon diagnostics Pvt. Ltd., Navsari, Gujarat) was carried out as a rapid slide test. This diagnostic reagent kit was used for the detection of specific antibodies produced in response to the stimulation by specific antigens of Salmonella. The killed bacterial suspension was specifically "O" and "H" antigen of Salmonella. This will react with immunospecific antibodies which may be present in the patient's serum and agglutinated with the antigen to produce agglutination or clumps on the slide. According to the manufacturer's instructions in the test kit procedures were carried out. On the slide test, to one drop of the patient's serum on each circle was added one drop of antigens "O", "H", "AH", and "BH." It was then mixed well and agglutinated to be observed after 1 minute. The agglutination was visible within 1 minute and then it was proceeded for quantitative estimation. As positive values $\geq 1: 80$, antibody titers for " $\mathrm{O}$ ", " $\mathrm{H}$ ", " $\mathrm{AH}$ ", and "BH" antigens were considered.

\subsection{Analysis of the Data}

The present study generated data which were obtainable with descriptive statistics. The data were analyzed and the results are presented in tables and in percentage.

\section{RESULTS AND DISCUSSION}

\subsection{General Prevalence in Percentages}

The study included a total of 1,378 samples, out of which 384 samples were positive. Out of 384 positive cases, malaria positive were found in $95(24.7 \%)$ patients, typhoid fever positive were in $271(70.6 \%)$ cases, and in $18(4.7 \%)$ patients coinfections were found (Table 1).

\subsection{Gender-wise Prevalence in Percentages}

This study diagnosed 95 malaria-positive patients, out of which 69 were male $(72.6 \%)$ and 26 female (27.4\%). 271 patients were having typhoid fever, out of which male and female-positive were 123 and 148 patients, respectively. Both malaria and typhoid fever coinfection were found in 18 patients, out of which $4(22.2 \%)$ were female and $14(77.8 \%)$ were male (Tables 2 and 3$)$. 


\subsection{Age-wise Prevalence (\%)}

With regard to age-wise prevalence, among the total 95 malariainfected patients, $16-30$ years were $46.3 \%, 31-45$ years were $17.9 \%, 46-60$ years were $13.7 \%, 1-15$ years were $11 \%$, and $61-$ 75 years were $10 \%$. Among the total 271 typhoid patients, 16-30 years were $42.8 \%, 31-45$ years were $27.3 \%$, 46-60 years were $12.5 \%, 1-15$ years were $8.5 \%$, and $61-75$ years were $6.3 \%$. In patients with coinfections (18) of typhoid and malaria, $44.4 \%$ of the patients were found in the age group of 16-30 years, $22.2 \%$ found in both age groups $31-45$ and $61-75$ years, and $11.1 \%$ of the patients were found of the 46-60 years age group (Tables 4 and 5).

Table 1. Overall prevalence (\%) of malaria, typhoid, and coinfection.

\begin{tabular}{lccc} 
Illness & $\begin{array}{c}\text { No. of test } \\
\text { samples }\end{array}$ & $\begin{array}{c}\text { No. of infected } \\
\text { samples }\end{array}$ & $\begin{array}{c}\text { No. of infections } \\
(\%)\end{array}$ \\
Malaria & 1,378 & 384 & $95(24.7 \%)$ \\
Typhoid & 1,378 & 384 & $271(70.6 \%)$ \\
Malaria + typhoid & 1,378 & 384 & $18(4.7 \%)$ \\
\hline
\end{tabular}

Table 2. Prevalence of both malaria parasite and typhoid fever infections according to sex.

\begin{tabular}{lccc} 
Sex & $\begin{array}{c}\text { Total samples } \\
(\mathbf{1 , 3 7 8 )}\end{array}$ & $\begin{array}{c}\text { Number infected } \\
\text { with malaria (\%) }\end{array}$ & $\begin{array}{c}\text { Number infected } \\
\text { with typhoid fever } \\
(\%)\end{array}$ \\
Male & $699(50.7 \%)$ & $69(72.6 \%)$ & $123(45.4 \%)$ \\
Female & $679(49.3 \%)$ & $26(27.4 \%)$ & $148(54.6 \%)$ \\
Total & $1,378(100 \%)$ & $95(100 \%)$ & $271(100 \%)$ \\
\hline
\end{tabular}

Table 3. Prevalence of both malaria and typhoid fever coinfection according to sex.

\begin{tabular}{lcc} 
Sex & Total number tested & $\begin{array}{c}\text { Number infected with coinfection } \\
(\%)\end{array}$ \\
Male & 18 & $14(77.8 \%)$ \\
Female & 18 & $4(22.2 \%)$ \\
\hline
\end{tabular}

Table 4. Incidence of coinfection in the age groups.

\begin{tabular}{cc} 
Age group & No. infected with coinfection $(\boldsymbol{n}=\mathbf{1 8})$ \\
$1-15$ & 0 \\
$16-30$ & $8(44.4 \%)$ \\
$31-45$ & $4(22.2 \%)$ \\
$46-60$ & $2(11.1 \%)$ \\
$61-75$ & $4(22.2 \%)$ \\
\hline
\end{tabular}

The major public health problem of malaria and typhoid is still present in tropical areas. The high prevalence of coinfection of typhoid and malaria in the tropic are also common; however, the mechanism of action to elucidate the relationship among malaria and typhoid fever are not identified [21].

In this study, out of 1,378 patients, malaria was diagnosed in 95 (24.7\%), typhoid fever in $271(70.6 \%)$, and coinfection of malaria and typhoid fever in 18 (4.7\%). In this study, male and female malaria patients who reported positive were $72.6 \%$ and $27.3 \%$, respectively. A similar percentage was reported in the study on Azia and Umudioka people in Anambra state, wherein 76\% were male and $62 \%$ were female [22].

The total typhoid fever cases were 271 , of which male and female were $45.4 \%$ and $54.6 \%$ respectively. The study carried out in Ekwulumili Community, Anambra State, Southeastern Nigeria, recruited 200 participants; $40(20.0 \%)$ were positive for malaria and $11(5.5 \%)$ tested positive for typhoid fever. Of these 11 cases that had typhoid, $2(18.18 \%)$ were male and 9 were female $(81.82 \%)$ [23]. Another study of coinfection of malaria and typhoid fever in Nigeria of Obuda-Aba residents typhoid positivity was present in $47.5 \%$ of 120 male and $38.4 \%$ of 125 female participants [22].

The present study found $4.7 \%$ prevalence of typhoid and malaria coinfection, and a similar low prevalence of $4 \%$ was reported in Dhir District of Pakistan [24]. 3.9\% prevalence was reported by Afoakwah et al. [25] in Ghana. A similar study reported the overall coinfection rate of $5.0 \%$ (10 out of 200) (2 male and 8 female) among the Ekwulumili Community in Nigeria [22].

In some countries, general practitioners/clinicians prescribe antimalarial drugs or anti-typhoid drugs without a diagnostic test. Thus, proper diagnosis is essential for the management of such fever cases which will save treatment cost and unnecessary use of antibiotics [26]. In contrast to our study, the prevalence of both malaria and typhoid fever coinfection was reported to be high in residents of Obuda-Aba, Abia State of Nigeria. 45 (37.5\%) out of 120 males, 55 (44.0\%) out of 125 females, and $105(42.86 \%)$ of 275 total cases had coinfection.

The relationship between poor sanitary system with occurrence of elevated malaria and typhoid fever coinfection cases are reported by various researchers. Various host and environmental factors like age, occupation, water quality and unhygienic surroundings are related to malaria-typhoid coinfections [27]. On the other side, low rainfall and dry climate can decrease the coinfection rate [28]. Coinfection was high ( 8 out of 18 , i.e., $44 \%$ ) in the age group of $16-30$ years and was low ( 2 out of 18 , i.e., $11.1 \%$ ) in the $46-60$ years age group in the present study. No coinfection was found in

Table 5. Prevalence of malaria parasite and typhoid fever patients according to age groups.

\begin{tabular}{cccc} 
Age group in years & $\begin{array}{c}\text { Number of } \\
\text { tested }\end{array}$ & $\begin{array}{c}\text { Number of malaria infected in \% } \\
(\boldsymbol{n}=\mathbf{9 5})\end{array}$ & $\begin{array}{c}\text { Number of typhoid fever infected (\%) } \\
(\boldsymbol{n}=\mathbf{2 7 1})\end{array}$ \\
$1-15$ years & 100 & $11(11.6 \%)$ & $23(8.5 \%)$ \\
$16-30$ years & 595 & $44(46.3 \%)$ & $116(42.8 \%)$ \\
$31-45$ years & 340 & $17(17.9 \%)$ & $74(27.3 \%)$ \\
$46-60$ years & 208 & $13(13.7 \%)$ & $34(12.5 \%)$ \\
$61-75$ years & 108 & $10(10.5 \%)$ & $17(6.3 \%)$ \\
\hline
\end{tabular}


age group of 1-15 years. This was in contrast to the study carried out in Ekwulumili Community of Southeastern Nigeria where the 1-10 years age group had a coinfection rate of $11 \%$, which was maximum, and a $2.8 \%$ prevalence rate was reported in the $51-60$ age group.

The epidemiology of febrile illness in tropical countries is changing due to improvement in sanitation and good hygienic practices. The global burden of typhoid fever is estimated by indirect parameters and actual incidence is difficult to determine. Malaria incidence is related to local change in climate conditions and rainfall. However, generation of new data and evidences in relation to these diseases are important as it may help public healthcare authorities to take necessary actions [29].

\section{CONCLUSION}

The study revealed that the typhoid prevalence rate is higher than malaria in patients with fever at a tertiary care hospital, Vadodara. Of the total infections, $4.7 \%$ of the cases had both malaria and typhoid coinfection. Both diseases were misdiagnosed because most of the cases had similar symptoms and also without laboratory test. Vector control, proper hygiene, and public health education are the preventive measures that are necessary to control these both diseases.

\section{ACKNOWLEDGMENT}

The authors would like to acknowledge with much appreciation the important role of Dr. S. L. Lakhani, Professor, Department of Microbiology, SBKS MI \& RC, for her vital suggestions in planning and completion of this study.

\section{CONFLICT OF INTERESTS}

The authors declare that they have no conflict of interests.

\section{AUTHORS' CONTRIBUTION}

All the listed authors have made substantial, direct, and intellectual contributions to the work, and approved it for publication.

\section{FUNDING}

There is no funding to report.

\section{ETHICAL APPROVAL}

The study was approved by the Institutional Ethics Committee (IEC: no: SVIEC/ON/2015/15011) SBKS MI \& RC Sumandeep Vidyapeeth Deemed University, Gujarat, India.

\section{REFERENCES}

1. Ibrahim S, Yacouba S, Wenceslas BW, Constant S, Da F, Soufiane SD, et al. Malaria and typhoid fever coinfection in the Hospital University of Bobo-Dioulasso, Burkina Faso. J Parasite Res 2019;1(1):1-18. Available via www.openaccesspub.org JPAR CC-license; https://doi. org/10.14302/issn.2690-6759.jpar-19-3081

2. World Health Organisation. Malaria key facts. WHO Press, Geneva, Switzerland, 2020. Available via https://www. who.int/news-room/ fact-sheets/detail/malaria
3. Panigrahi K. A comparative study of peripheral blood smear, QBC and antigen detection test in diagnosis of malaria, in a tertiary care hospital. Int J Res Rep Med Sci 2013;3(3):35-38.

4. Mogasale V, Maskery B, Ochiai RL, Lee JS, Mogasale VV, Ramani $\mathrm{E}$, et al. Burden of typhoid fever in low-income and middle-income countries: a systematic, literature-based update with risk-factor adjustment. Lancet Glob Health 2014;2(10):e570-80

5. Wain J, Hendriksen RS, Mikoleti ML, Keddy KH, Ochiai RL. Typhoid fever. Lancet 2015;385(9973):1136-45.

6. World Health Organisation. Typhoid fever. WHO Press, Geneva, Switzerland, 2020. Available via https://www.who.int/news-room/qa-detail/typhoid-fever . Accessed 12/05/20.

7. Shrihari N. Laboratory diagnosis of malaria, enteric fever and dengue infections in pyrexia of unknown origin cases at tertiary care hospital. Int J Innovative Drug Discovery 2014;4(3):162-3.

8. Anagha K, Deepika B, Shahriar R, Sanjeev K. The easy and early diagnosis of typhoid fever. J Clin Diagn Res 2012;6(2):198-9.

9. Sood NK, Jain MM, Patel S, Mandalia A, Bhavsar HK. A prospective comparative study of semi-quantitative slide Widal test $\&$ quantitative tube Widal test. Natl J Integr Res Med 2014;5(6):73-7.

10. Birhanie M, Tessema B, Ferede G, Endris M, Enawgaw B. Malaria, typhoid fever, and their coinfection among febrile patients at a Rural Health Center in Northwest Ethiopia: a cross-sectional study. Adv Med 2014;2014:531074.

11. Uneke UK. Concurrent malaria and typhoid fever in the tropics: the diagnostic challenges and public health implications. J Vector Borne Dis 2008;45(2):133-42.

12. Nsutebu EF, Martins P, Adiogo D. Short communication: prevalence of typhoid fever in febrile patients with symptoms clinically compatible with typhoid fever in Cameroon. Trop Med Int Health 2003;8(6):5758.

13. Federal Republic of Ethiopia, Ministry of Health. National malaria guidelines. 3rd edition, Scientific Research Publishing, Addis Ababa Ethiopia, 2012.

14. Cheesbrough M. District laboratory practice in tropical countries (Part1). Advances in Medicine. 2nd edition, Cambridge University Press, Cambridge, UK, 2006, 8.

15. WHO. Guidelines for the treatment of malaria. 2nd edition, WHO, Geneva, Switzerland, 2010.

16. Leslie T, Mikhail A, Mayan I, Anwar M, Bakhtash S, Nader M, et al. Overdiagnosis and mistreatment of malaria among febrile patients at primary healthcare level in Afghanistan: observational study. BMJ 2012;345:e4389.

17. Hassan SEDH, Abd Elrahium DH, Mohammed-Elhassan EB, Malik EM, Adam I. "Fluorescence microscope (Cyscope) for malaria diagnosis in pregnant women in Medani Hospital, Sudan. Diagn Pathol 2011;6(1):1-5.

18. Uzochukwu BSC, Chiegboka LO, Enwereuzo C, Nwosu U, Okorafor $\mathrm{D}$, Onwujekwe $\mathrm{OE}$, et al. Examining appropriate diagnosis and treatment of malaria: availability and use of rapid diagnostic tests and artemisinin-based combination therapy in public and private health facilities in south east Nigeria. BMC Public Health 2010;10:486.

19. Mackie TJ, McCartney JE, Collee JG. Mackie \& McCartney practical medical microbiology/. Harcourt Health Sciences, Churchill Livingstone, New York, 1996.

20. Warrell DA, Gilles HM. Essential malariology book. 4th edition, CRC Press, Boca Raton, FL, 2002.

21. Ukaegbu CO, Nnachi AU, Mawak JD, Igwe CC. Incidence of concurrent malaria and typhoid fever infections in febrile patients in Jos, Plateau State Nigeria. Int J Sci Technol Res 2014;3:157-61.

22. O'woma OO, Chigozirim UP, Gloria NU. Prevalence of malaria and typhoid fever co-infection: knowledge, attitude and management practices among residents of Obuda-Aba, Abia State, Nigeria. Am J Public Health Res 2015;3:162-6; https://doi.org/10.12691/ajphr-3-4-6 2015;3(4):162-166 
23. Onyido $\mathrm{AE}$, Ifeadi $\mathrm{CP}$, Umeanaeto $\mathrm{PU}$, Irikannu $\mathrm{KC}$, Aribodor $\mathrm{DN}$, Ezeanya, et al. Co-infection of malaria and typhoid fever in Ekwulumili community Anambra State, Southeastern Nigeria. N Y Sci J 2014;7(7):18-27.

24. Qureshi AE, Khan Z, Khan L, Mansoor A, Minahs R. Prevalence of malaria, typhoid and co-infection in district dir (lower), Pakistan. Biosci J 2019;35(1):317-25.

25. Afoakwah R, Acheampong DO, Boampong JN, Sarpong-baidoo M, Nwaefuna EK, Tefe PS. Typhoid malaria co-infection in Ghana. Euro J Exp Biol 2011;1:1-6.

26. Mbuh FA, Galadima M, Ogbadu L. Rate of co-infection with malaria parasites and Salmonella typhi in Zaria, Kaduna State, Nigeria. Ann Afr Med 2003;2(2):64-7.

27. Nwuzo A, Onyeagba R, Iroha I, Nworie O, Oji A. Parasitological, bacteriological, and cultural determination of prevalence of malaria parasite (Plasmodium falciparum) and typhoid fever co-infection in Abakaliki, Ebonyi State. Sci Res Essays 2009;4:966-71.
28. Storey HI, Huang Y, Crudder C, Golden A, De los santos T, Hawkins K. A metaanalysis of typhoid diagnostic accuracy studies: a recommendation to adopt a standardized composite reference. PLoS One 2015;10(11):e0142364; https://doi.org/10.1371/journal. pone. 0142364

29. Crump JA, Luby SP, Mintz ED. The global burden of typhoid fever Bull World Health Organ 2004;82(5):346-53.

How to cite this article:

Vasava SD, Lakhani SJ, Lakhani JD. Prevalence of malaria and typhoid fever and coinfection in all febrile patients attending at tertiary care hospital in Vadodara. J Appl Biol Biotech 2021; 9(05):136-140. 